\title{
Lexical Quantors: From Term to Discursive Practice
}

\author{
Elina Kushch \\ Theory and Practice of Translation Department, Zaporizhzhia Polytechnic National University, Zaporizhzhia, Ukraine
}

Vasyl Bialyk

Department of Communicative Linguistics and Translation, Yuriy Fedkovych Chernivtsi National University, Chernivtsi, Ukraine

Olena Zhykharieva

O. M. Morokhovsky Department of English Philology, Translation and Philosophy of Language, Kyiv National Linguistic University, Kyiv, Ukraine

Viktoriia Stavtseva

Department of the English Language and Translation, Kyiv National Linguistic University, Kyiv, Ukraine

Svitlana Taran

Department of Communicative Linguistics and Translation, Yuriy Fedkovych Chernivtsi National University, Chernivtsi, Ukraine

\begin{abstract}
The paper looks into the emergence of terms and neologisms related to COVID-19 outbreak, which are treated as lexical quantors (LQs). A LQ, as a linguistic nominative unit, reflects the amount of language knowledge (LK) represented in a certain segment of language worldview (LWV). It is represented by a word or a phrase, which constitutes some quantum of information to designate a certain segment of LWV. It has a systemic character and is reflected in the semantics of a linguistic unit. This research is aimed at exploring COVID-19 lexical quantors both in terminological and general vocabulary aspects and it defines the major language concepts for special purposes (LSP). It is characterized by the word formation means expressing all types of LK with the prevalence of a denotative special meaning. General COVID-19 lexical units employ all word formation means to render both denotative and connotative components of LQs meanings revealing also social, cultural, and axiological aspects of LK. The boundary between COVID-19 terminology and general lexical units is quite blurred when the transition from one layer of vocabulary to another is observed. Word formation is viewed as the process of constructing LQs in terms of aggregated, condensed and modified knowledge means. In conclusion, the informative potential realization of $L Q$ is manifested in various discursive practices, namely: media, politics, and public service announcements (PSA) that embrace both linguistic and socio-cultural characteristics of communication.
\end{abstract}

Index Terms - Covid-19; discursive practice, lexical quantor, term, word formation

\section{INTRODUCTION}

The comprehension of human cognitive abilities in language organizing, processing, and conveying has always been one of the major goals of cognitive linguistics (Fauconnier, Turner, 1998, 2002; Langacker, 1987, 1991a, 1991b, 2000; Shepard, 1988; Ungerer, Schmidt, 1996). Cognitive linguistics is closely linked to the concept of knowledge representation in consciousness structures that reflect the surrounding world in human mind by virtue of language means. It is largely based on the theory of nomination according to which the process of nomination establishes the connection of linguistic elements with the facts of reality and includes the conceptual class of nomination into a certain system of linguistic signs (Onysko, Michel, 2010). A wide range research dwells upon different problems of cognitive word formation trying to integrate it into concepts like cognitive grammar, form-meaning iconicity and conceptual blending (Arndt-Lappe et al., 2018; Plag, 2002; Marshak et al., 2000; Onysko, Michel, 2010). Despite considerable advances in various language areas study in cognitive aspect, the problems of knowledge representation in the processes of word formation in relation to comprehension of language nature, understanding the ways of its evolution and acquisition, the dynamic processes in the language development and its use in communication in a creative way have not been sufficiently elucidated.

The objective of the article is to give a brief outline of word formation means of new lexical units emerged under COVID19 pandemic. The research focuses on the epistemological aspect of a nominative unit which is viewed as a LQ containing some quantum of LK. The nominative units represented by LQs are classified into LQ-nominatives, LQ-adjectives, LQverbatives, and LQ-adverbatives reflecting aggregated, condensed and modified knowledge. 
In accordance with the tasks of the research the types of different word formation means as the components of appropriate LK are studied. COVID-19 lexical quantors are considered both in terminological and general vocabulary aspect. Sharing common word-building techniques, terminology and general vocabulary are closely interrelated and intertwined making the boundaries between them rather fuzzy. Finally, COVID-19 lexical quantors are analyzed in three discursive practices, namely: media, political, and PSA which are characterized by one common information dominant and are closely interlinked.

\section{THEORETICAL BACKGROUND}

The structure of the surrounding world is reflected in human consciousness in the form of certain concepts (Langacker, 1991b). Conceptualization issues have been traditionally considered by semantics and grammar (Langacker, 1987). Still, recent research on conceptualization mechanisms proves that word formation may be viewed as a conceptualization means of the surrounding world too (Langacker, 2000). First and foremost, this refers to termformation (Wüster, 1991) as the terminoelements are the carriers of information about a few concepts in special areas of human activity (Bialyk, 2011). This special LK reflects the experience and idea of the experts in a certain area and serves as its storing and transferring means.

From the view of cognitive linguistics, word formation patterns are an analogue or simulacrum in the system of knowledge representation in LQ. LQ is of a prototypic nature as in the process of its genesis and creation it employs already available and formed properties in a language system and inherits the meanings which are stipulated by them (Bialyk, 2019b). LQ, as a prototypical linguistic unit, determines a prototypical dynamic situation resulting in a change. The general basic word-stock, as a rule, gives a classification of situations, primarily, types of changes as well as events which might happen with objects.

The fragmentation of the world may occur not only with help of words but also word formation elements constituting LQ (Byalyk, 2012). Cognitive approach to word formation study presupposes thorough study of the peculiarities of the highlighted objects of reality, its adequate conceptualization. Some scholars (Plag, 2002) argue that a certain conceptual entity underlies a word formation structure. The word-forming elements are characterized by, at least, three aspects: semantic (semantics of the components and word-forming meaning), functional (combinability with other word forming elements), and cognitive (conceptualization and mental processing) (Bialyk, 2019a). The subject of cognitive linguistics is a human cognition, so a person acts like the generator of the meanings of words, s/he chooses their own way of interpreting reality and way of presenting the results of cognition, that is manifested in the ways of occasional word formation, which is a means of access to the mental processes that occur in the human brain. Therefore, cognitive semantics can be defined as a science of general principles which control mental processes (Shepard, 1988) and study the ways of cognition of the world and the role of language in their application (Fauconnier, Turner, 2002).

While dealing with a word-forming structure of a LQ, we observe the formation of a lexical meaning on the basis of some available cognitive structure possessing some concepts, such as subjectivity, property and others that show the interaction of life and language. Word formation from the cognitive point of view aims at studying and modeling the structure of human knowledge underlying the nominative structure of a LQ. It also implies elucidation of interaction of mind, language, and reality in the act of a concept nomination as well as revealing cognitive mechanisms and language means to designate various segments of the LWV (Bialyk, 2019a).

One of the peculiarities of a word-stock is its relevance with phenomena of reality. It is in the lexicon that all changes in social life are reflected. The word-forming diversity of LQs causes the complexity and mobility of relations among them in a word-stock. The evolution of LQs can be observed in different directions, for instance, homonymy, merging of several words into one word, borrowings etc. and classified according to the following criteria: morphological, structural and semantic.

The morphological criterion reflects a lexico-grammatical division of language continuum and linguistic means of the reality that is being described. This criterion implies taking into account the meaning, form, and function of LQ. The meaning of LQ here is a lexical category indicating to the general meaning of the whole group of LQs, such as subjectivity, action, property, mode of action. The morphological characteristics are the form of LQs, whereas the function presupposes the combinatory properties of LQs and their syntactic role in a proposition. The major characteristic of this criterion, therefore, is categorization of LQ in accordance with lexico-grammatical classes and their formal indicators. So, LQs are divided into LQ-nominatives, LQ-verbatives, LQ-adverbatives, and LQadjectivatives.

The structural criterion indicates the complexity of a word formation structure of a LQ the elements of which are correlated with the number of minimal LK in a LQ. Thus, LQs are divided into LQ-univerbs / simple words, LQderivatives, LQ-composites, and LQ-abbreviations.

The semantic criterion shows the deep semantic factors and direct connection of LQs with extralingual reality. Such a connection may concern the nucleus of the semantic structure of a LQ and be characterized by denotative correlation or its periphery indicating to the varieties of manifestation of reality, which are usually realized in a secondary nomination. With this criterion a LQ contains LK obtained as a result of expanding LQ meaning through the changes in the denotative or connotative components resulting in LQ-denotatives, LQ-connotatives with their further subdivisions into LQ-amelioratives, LQ-pejoratives, LQ-metaphors, and LQ-metonyms. The latter types are most important in revealing 
cognitive peculiarities of word formation processes. They are involved in imagery reinterpreting of human experience and substituting conventional concepts for new ones to denote changes happening in the world.

Alongside with the study of language as a functional dynamic system the regularities of its functioning are very important in discursive practices. By discursive practices Foucault (1972) means power relations in the society; how is a relationship created by asserting power through the use of language. The 'discursive practice' dimension, like 'interaction' in the 'text-and-interaction' view of discourse, specifies the nature of the processes of text production and interpretation, for example, which types of discourse (including 'discourses' in the more socialtheoretical sense) are drawn upon and how they are combined. The 'social practice' dimension attends to issues of concern in social analysis such as the institutional and organizational circumstances of the discursive event and how that shapes the nature of the discursive practice, and the constitutive / constructive effects of discourse referred to above (Fairclough, 1992).

Word formation peculiarities of COVID-19 lexical quantors may be considered from, at least, two aspects: terminological (medical discursive practice) and sociocultural (political, media, PSA discursive practices). Each discursive practice is characterized by a certain communicative intention aimed at revealing some knowledge / information load of the message.

The research is based on qualitative approach to the study of lexical quantors. The semasiological method focuses on the analysis of word formation units; the specification of the individual components and morphological structures of LQs as naming units. It usually concentrates on the question concerning meanings of word-formative types of LQs. The onomasiological method focuses on the process of coining new nominative units represented by LQs. The starting point is the concept and conceptual meaning, or it may be set into the extra-linguistic reality as an object of the process of denomination. The communicative-discursive method develops the principles of communication theory and discourse analysis as manifested in discursive practices, where new nominative units are transforming at the syntactic level, showing how a new LK represented by LQ used in a social context.

\section{RESUlTS AND DiSCUSSION}

\section{A. COVID-19 Terminology}

Terminological aspects of Coronaspeak are manifested in term-formation and term functioning in medical discursive practice. A term is considered to be a word or a word combination used to designate a special concept in a language for LSP. Traditionally, terms form a system of terms / a terminological system of a certain special field of human activity. The boundaries of COVID-19 terminology, though, are rather obscure as it combines and uses terminologies from other medical areas and even other terminologies (psychology, epidemiology, sociology). Besides, this terminology covers both the terms in strict sense, i.e. words denoting special concepts with exact definitions of the concepts designated in LSP (remdesivir, camostat, mesilate, regeneron, epithelial cells, virus, oxygen therapy, etc.), and loose terms which are close to the words of generally used lexical units and phrases (stay at home, suspected case, shelter in place, confirmed case, surgical mask, etc.). Basically, it is possible to assert that COVID-19 terminology arises from general medical terminology and focuses on the peculiarities of COVID-19. All the terms within this terminology may be divided into four large groups representing different aspects of COVID-19: PREVENTION, INSTRUMENT, DISEASE, and CONSEQUENCE. The PREVENTION group of terms presents the prophylactic measures to prevent from the disease (face mask, face shield, lockdown, sanitizer, social distancing, etc.) INSTRUMENT terms include appliances, machines, devices, objects etc. used in treatment of the disease, its diagnosis (ventilator, Hazmat suit, personal protective equipment, nasopharyngal swab, oropharyngeal swab, throat swab, isolation gown, contact tracing etc.). DISEASE group of terms embraces the major characteristics both of the disease and a patient (symptomatic, asymptomatic, confirmed case, acute respiratory distress syndrome, wheezing, incubation, dyspnea, patient zero, morbidity, airborne transmission, etc.). Finally, CONSEQUENCE group terms shows the result of the disease treatment (flatten the curve, mortality rate, spike protein, stroke, seizure, blood clots, Guillain-Barre syndrome, shortness of breath, liver problem, kidney problem, post-traumatic stress syndrome, etc.). Each of the aforesaid groups is characterized by peculiar termformation characteristics pertaining to different types of LK such as aggregated, condensed, and modified knowledge.

Aggregated knowledge is understood as the process of adding (augmentation) meanings represented by LQ structural constituents and expressed by word formation means (affixation, compounding). While LQs represented by non-derived words serve to name certain actions and objects identifying them with a specific fragment of the world; the derived words, alongside with the naming function, indicate their connection with an action, property or object as well as their relationship. In the terminology under study aggregated knowledge is represented by affixation (prefixation and suffixation) as a term-formation means and compounding.

Affixal terms of COVID-19 terminology do not only single out some fragments of reality and the information about it, like simple, non-derived LQs do, but indicate the object's connection with action, property, relationships between them. The meanings of such terms are easily decoded even without a context owing to productive patterns according to which they are formed. It is quite obvious that affixation is a powerful means of expressing LK in a LQ-term and replenishment of a word-stock in general. Prefixes and suffixes add to the thematic connotation, i.e. a quantum of LK added to the word stem. This requires both the knowledge of "an old" root of the word and that of an affix (a prefix, a semi-prefix, a suffix, a semi-suffix). Among the most widely used affixes with the COVID-19 term-formation are as 
follows: -or (ventilator); -ist (virologist); -ation (immunization); -al (serological); -ity (pathogenicity); -ic (asymptomatic); -ing (wheezing); out- (outbreak); pan- (pandemic); re- (reproductive); anti- (antibodies).

Compounding like affixation may be considered as an additive means of transferring LK in a LQ represented by a term, extensive way of joining LQ elements indicating to the informational potential of a LQ. It should be noted that despite the productivity of this way of term / word formation in general, COVID-19 terminology does not employ compounding extensively, save for some terms like coronavirus, airborne, bronchoalveolar and so on. The latter example is the evidence of a combining form use (-o letter) in the middle of a LQ-compound term. It is quite obvious that affixal LQ-terms and compounds are endowed with more informational load than LQ-simple terms. At the same time they manage to preserve the integral form, which is important in the naming process of concept properties.

Condensed knowledge is treated in this article as concentration (amalgamation) of meanings in the process of downsizing of a word formation structure containing the implicit information in its elements (various shortenings, abbreviations, blending). In COVID-19 terminology the shortening of phrases may be accounted to two factors: the need to label a concept in a concise way for practical use and, secondly, the functioning of the law of language economy to optimize the way of information exchange.

For the terminology under study various types of letter abbreviations are typical, such as $S A R S, A R D S, M E R S, B A L$, $T A$ meaning consequently 'secure acute respiratory syndrome', 'acute respiratory distress syndrome', 'Middle East respiratory syndrome', 'bronchoalveolar lavage', 'tracheal aspirate'. Very often letter abbreviations may be combined with numerical components: SARS CoV-2, ACE 2 receptor, $N 95$ respirator, COVID-19, 2019-nCov. In these cases abbreviations form a complex verbal and graphical unity (abbreviation + numerical component + a word) that facilitates understanding the content of the concept designated by LQ. Some terms like COVID-19 may reveal even regional varieties when all initial letters are capitalized in American English, whereas only the first letter is capitalized in British English (Covid-19). It is not rare to observe instances when the abbreviated terms are used together with nonabbreviated ones (PCR test); some of their parts may be presented with a lowercase letter (nCov - novel Coronavirus) or may refer to a grammatical category (NPIs - nonpharmaceutical interventions).

The linguocreative idea of "packing" knowledge in a concise way is vividly seen in the use of blending or 'portmanteau' terms in COVID-19 terminology (coronacation - coronavirus + vacation). Blended terms are LQs which are formed by means of 'splinters fusion' of two or more LQs, or 'a fusion' of the reduced part of one LQ with the whole form of another LQ. The reduced 'splinters' of LQs which are used in the process of blending 'absorb' the semantics of their prototypes. So their semantics is formed in terms of 'overlapping meanings' of their components and may result in total meaning of all the components ('virologist' - an expert in viruses) or contain some new information ('hydroxychloroquine' - 'hydroxy' which is clipped from 'hydroxyl' and 'chloroquine'; thromboembolism - 'thromb' and 'embolism', 'zoonosis' - 'zoonotic' and 'disease').

The bulk of a word-stock is characterized by modified knowledge implying the process of information transfiguration, the modification of the content (conversion, borrowings, backformation, and semantic derivation).

Many COVID-19 terms are predominantly borrowed from Greek and Latin ('epidemic', epidemiology', 'pandemic', 'sputum', 'virus', 'zoonosis', 'pneumonia'). Still, there are borrowings from other languages, for example French word 'triage', standing for 'a process for sorting injured people into groups based on their need for or likely benefit from immediate medical treatment', (American Heritage, 2007), another LQ of French origin 'lavage' - 'a washing, especially of a hollow organ, such as the stomach or lower bowel, with repeated injections of water' (American Heritage, 2016), though they are not so numerous as compared to Greco-Latin elements.

The modified knowledge involves a quite large layer of the lexicon and implies the process of information change, the modification of the content of a LQ. Thus, such COVID-19 terms like 'herd immunity', 'pool sampling', 'second wave', 'peak', 'incubation period', as the very word 'coronavirus' and many others, undoubtedly, possess some imagery components of meaning in the process of its transference based on analogy or likeness of the properties of the concept designated by the term. These prototypical properties are ascribed to new concepts and facilitate the language user to comprehend the amount of information any concept contains.

Terms are considered to be monosemantic (e.g. 'oxygen') and this is one of the requirements for regular terms. But in practice we can observe a polysemantic nature of terms even within one field of human activity, COVID-19 terminology being no exception (for instance, 'shortness of breath' and 'dyspnea'). Synonymic LQ-terms are especially common for multi-component terms (three-four-component terms) when due to the law of language economy these terms are abbreviated ('polymerase chain reaction test' - 'PCR test'; 'personal protective equipment' - 'PPE', nothing to say about 'COVID-19', which is presented by its variants - 'Wuhan virus', 'China coronavirus', '2019-nCov', 'SARS CoV-2').

The COVID-19 terminology, thus, is presented predominantly with aggregated and condensed knowledge for PREVENTION and INSTRUMENT groups of terms and modified knowledge for DISEASE, and CONSEQUENCE groups of terms.

One of the major properties of any language is striving for economical use of its resources. This gives rise in quantitative growth of language units including terms, conventional words, or LQs in general, which in its turn, eventually, results in secondary nomination. Language itself tries to find already available means to designate new concepts. 


\section{B. COVID-19 General Lexical Units}

As it has been stated earlier in this paper, the boundary between terminology and general lexical units is rather fragile. Terminology contributes much to general word-stock replenishment and general lexical units enter the terminological space of a LSP. This is a striking feature of the COVID-19 lexical units in particular. The outbreak of COVID-19 pandemic has affected every aspect of a human life on the global scope. The failure to find effective treatment for the disease and, as a result, the failure in positive solving social, political, economic, cultural and other problems in modern world have focused people's attention on the source of the disaster. The COVID-19 pandemic has brought about drastic changes in human social behavior, which is immediately reflected in language use, in the peculiarities of representing new LK in nominative units.

The general COVID-19 lexical units may be divided into five large groups: PREVENTION, INSTRUMENT, DISEASE, CONSEQUENCE, and, finally, BEHAVIOR. The latter group was not included into the terminological sphere of COVID-19 pandemic but is important for general lexical units as it implies various forms of social behavior under the conditions of global disaster, COVID-19 being the one.

The nominative units represented by LQs of PREVENTION group include aggregated knowledge word-forming means, such as affixation and compounding ('elbow bump'/ 'elbump' - a gesture akin to a high five, a safe way to greet another person; 'drive through testing' - testing for COVID-19 through car windows; 'disinfectant' - a chemical that kills bacteria; 'immunization' - being made immune through vaccination). Condensed knowledge word-building means are peculiar for the CONSEQUENCE, BEHAVIOR, and DISEASE groups ('maskne' - an acne outbreak caused by facial coverings; 'doomscrolling' - the process of skimming anxiety-inducing pandemic-related stories on a smartphone).

The COVID-19 pandemic has shaped the life of the community in a totally different way in comparison with preCOVID times. This is reflected in units which react instantly to the changes in all spheres of life. Many of the new coined words have an imagery component at the basis of their formation. The very word 'coronavirus' as a type of the viruses family was called due to the resemblance the Sun's halo, known as the solar corona in Latin meaning "crown" or "wreath". The expressive force of the LK underlying the naming of new concepts is clearly observed within all groups of LQs of general lexical units.

So, for instance, the PREVENTION group of LQs may include some mitigation measures to prevent from falling ill and this requires observing 'social distancing', wearing 'face masks' properly. One should not be a 'maskhole' or to have one's 'face naked'. It is mandated to keep to 'hand hygiene', using a 'sanitizer'. People prefer to avoid 'superspreaders', i.e. highly contagious individuals who can infect a large number of people. They obey 'stay at home' orders and prefer 'contactless' delivery when purchased items are left at the entryway of a home rather than handing them directly to them. Even with this small extract of using LQs to designate new dimension of everyday life under COVID-19 pandemic we can easily trace the huge expressive potential of the nominative units to designate new norms of human behavior. These words are not new, in fact, they only denote new dimension of reality caused by COVID-19 pandemic. Very often we can observe how terms enter general lexicon and, vice versa, when conventional words are used as terms in LSP. This fact may be the result of functional mobility of lexicon, its movement from periphery of the system (from LSP) to its nucleus (general units), then from the nucleus to its periphery and moving inside the periphery. This might be considered as some dynamic scheme of verbocreation and interpenetration of the lexicon layers belonging to different functional styles. This is one of the reasons that there is not a strict demarcation line between terminology and general lexical units. The functional and semantic development of the LQs may be reduced to three directions: terminologization when LQs are used in a special meaning in LSP, trans-terminologization or reterminologization, when a LQ migrates from one terminological system to another, and determinologization when terms are turned into conventional words. The COVID-19 pandemic has caused a boom of new coinages based on the available resources to reflect different segments of LWV as well as extensive use of terminological units by laypeople. The determinologization process may be exemplified by the use of once obscure medical terms in everyday speech, including the names of some antiviral medication, such as 'dexamethasone' or 'hydroxychloroquine', or medical terms, such as 'asymptomatic transmission', 'infectious disease' and so on. The terminologization may be illustrated with the following LQs: 'flatten the curve', 'lockdown', 'cluster', 'vehicle' etc. while a great deal of general medical terms share the COVID-19 terminology ('mortality rate', 'morbidity' etc.) or have migrated from other terminological systems ('Hazmat suit', 'airborne', 'alcohol').

Semantic LQs are formed as a result of the secondary use of nominative units to designate the concepts associated in our consciousness with some generalization. Inner semantic relations within a nominative unit are the means of organization and fixing of conceptual structures in our consciousness. Traditionally, these inner relations are described in terms of metaphors and metonymy. The simulative relationships within a LQ polysemantic structure is represented by metaphor. In modern linguistics, metaphor is viewed as a cognitive phenomenon, an instrument of thinking, a fundamental technique of cognition and conceptualization of the reality which is peculiar only for homo sapiens (Lakoff, 1980). Our traditional conceptual system is metaphorical, in fact, as the processes of thinking are based on reconceptualization of human experience. The use of the available nominative resources in a language to label some concepts of reality is much stipulated by the associative relations between different referents. Thus, metaphor operates imagery and associative similarity which is peculiar only for this mechanism of modification of meaning. Metaphor is part and parcel of the modified LK which is embodied in a LQ ('herd immunity', 'hoarding', 'viral shedding', 'shield' 
etc.). There are also cases of metonymic transference of meanings in COVID-19 lexical units based on associations of really existing relations among the concepts and their contiguity ('to flatten the curve', 'slackers' etc.). The modified LK plays a decisive role in forming the cognitive content of LQs and reveals unlimited potential of verbocreation in all groups of the COVID-19 lexical units.

The Coronaspeak vocabulary has also shown the linguocreative basis of a language and its synergetic nature. It is common knowledge that a language is a self-developing and self-organized system, which is flexible and responsive to any social and cultural changes in a society. At the same time, it is governed by some linguistic norms, standards, and laws in performing its functions, among which informative, cognitive, communicative, and expressive are of utter importance. One of the most essential features of a language is the way of "packing" LK in the most concise and clear-cut way. This requires, in its turn, the most economical techniques of expressing LK verbally in a LQ, thus, giving way to various condensed / compressed forms of labeling concepts designated by LQs, such as shortening and blending. Basically, these forms of condensed LK represent the amalgamation of two or more concepts in one LQ and prove to be very productive in the COVID-19 lexicon (letter abbreviations: $B C-$ the period before coronavirus; $C D C$ - Center for Disease Control and Prevention; $P P E$ - personal protective equipment; $C F R$ - case fatality rate; $C P A P$ - continuous positive airway passage; $W F H$ - work from home; blending: 'pancession' - a pandemic-associated widespread economic recession; 'covexit' - an exit strategy permitting relaxing of confinement and economic recovery following coronavirus-related restrictions; 'covidpreneurs' - individuals or businesses succeeding in thriving and innovating in a pandemic environment; 'elbump'- an elbow contact in place of handshaking or other physical greeting; 'locktail hour' - a time allotted to consumption of cocktails while isolating (Thorne, 2020). The 'corona (virus)' and 'quarantine' are the dominants among the COVID-19 lexical units and are very prolific in forming various derivatives to render LK in LQs. Thus, 'corona' derivatives may be illustrated by the following examples: 'coronageddon' - a desperate end-of-time situation created by political, economic and social devastation due to coronavirus around the world; 'covideo' - a short video of a quarantined individual's child which could be emotional or loveable; 'covidanoid' - being paranoid of Covid-19; 'covidamin' - someone who neglects the necessary precisions and preventive recommendations for controlling hygiene related to Covid-19; 'covidarium' - a field hospital temporarily set up to house Covid-19 patients; 'covidcation' - when work or school gets cancelled because of Covid-19; 'covismart'- to adhere to public health regulations and social distancing in order to avoid the spread of the virus; 'covidcrazy' - the feeling of dejection and despondency caused due to the Covid-19 lockdown. And 'quarantine' may be represented by such examples: 'quarantigue' - fatigue due to spending too much time in isolation due to Covid-19; 'quarandating' - using cellular dating apps to meet people and go on virtual dates through platforms such as FaceTime; 'quarantanning' - sun bathing or using tanning equipment during confinement; 'quaran-stream' binge-watch TV series, movies while enduring lockdown; 'quaranteens' - the generation who will become teenagers in 2033-2034; 'quaranteams' - groups forming and performing - music or competing in quizzes for example - together virtually during lockdown; 'quaranqueens' - a woman excelling during lockdown, particularly one excessively cleaning and tidying; 'quarantrolls' - individuals sending malicious online messages in conditions of and/or referring to quarantine (Thorne, 2020).

The BEHAVIOR group of COVID-19 general lexical units is one of the most representational of all the six ones and embraces various aspects of social life and conduct under COVID-19 pandemic conditions. This group of LQs is closely interrelated with the rest analyzed groups (PREVENTION, INSTRUMENT, DISEASE, and CONSEQUENCE) due to the inclusion the behavioral patterns of a social individual into other spheres of the lexicon under study. Thus, the situation of COVID-19 pandemic imposes restrictions in social life, interpersonal communication, and behavior. People are homeworking and teleconferencing using a 'Zoom room' (part of one's home kept clean and inviting for use as videocalling background). They may put on 'upperwear' (clothing selected for display above the waist only) or infits (outfits worn in conditions of confinement) avoiding 'zoombombing' (hijacking and/or interrupting videoconferencing on the zoom platform) (Thorne, 2020). This type of social behavior is common during the pandemic both in relation to work and study, as, for instance, 'coronaviva' (a spoken examination or thesis defence taken online during lockdown) is a common phenomenon as well as 'homeference' (a virtual conference that participants can attend remotely) (Thorne, 2020).

There are many LQs of negative semantics pertaining to different groups of nominative units representing new LK. These LQs may be regarded as nonce-words or neologisms (see Aleksyeyeva et al., 2020) formed as a result of creative verbal potential of the language in response to new challenges caused by the pandemic. Among those units are slangwords: 'covidiot' - a person behaving irresponsibly in conditions of containment; 'morona' - a person behaving stupidly because of or during the coronavirus outbreak; 'coronalusional' - suffering from disordered thinking as a result of or during the Covid-19 crisis; 'zumped' - 'dumped' by a partner via videolink or otherwise online; 'coronasshole' - first applied in March 2020 to US panic buyers, then in June to US citizens refusing to wear masks, in July the synonym 'maskhole' began to trend on social media; 'maskulinity' - a macho refusal to wear a face covering and others (Thorne, 2020).

The social behavioral patterns of individuals during the pandemic are not limited to work or study but cover, in fact, every aspect of human activity: 'coronacation' - cessation of study or work due to the pandemic, viewed as a holiday; 'corona break' - a period of confinement envisaged as a short holiday; 'drivecation' - a holiday, typically in a 
motorhome, in one's own driveway; 'hamsterkaufing' - stockpiling and / or hoarding (adapted from German); 'coronaspeck' - extra girth resulting from overeating in confinement; 'quarandating' - using cellular dating apps to meet people and go on virtual dates through platforms such as FaceTime; 'spendemic' - a dramatic increase in online shopping by those confined during the coronavirus crisis; 'furlough merlot' - a red wine assuaging the anxiety of lockdown; 'lockdown locks' - long and / or unruly hair following months without cutting or styling; 'Blursday' - an undifferentiated day or date due to uncertainty after long confinement and isolation and others (Thorne, 2020).

Thus, the COVID-19 lexical units are characterized not only by a variety of word formation means to represent a new LK in LQs but also indicate its innovative, pragmatic, and communicative nature realizing the available resources of the language.

\section{COVID-19 LQs in Discursive Practices}

Cognitive characteristics of LQs are explicitly manifested in speech format which is represented by discursive practices. There have been chosen three types of discursive practices: media, politics, and PSA as an illustration for the research performed. However, there were no specific criteria for their selection and the very choice was much stipulated by the sufficient electronic data base available and the scope of topics these discursive practices cover. The brief overview of each discursive practice aims at giving its main characteristics and outlining the thematic dominants in the context of COVID-19. A discursive practice is understood in the article in Foucauldian term which implies its consideration as "the process through which [dominant] reality comes into being" (Foucault, 1972). It is important to emphasize that this term refers to a historically and culturally specific set of rules for organizing and producing different forms of knowledge and rules which, like the grammar of a language, allow certain statements to be made (Foucault, 1972). Media discursive practice in the COVID-19 context may be constitutive and transforming as it shapes understanding of events, makes impact on the audience attitudes and beliefs, thus, transforming the consciousness of those who are involved in it. The pandemic of COVID-19 disrupted the social order with sudden changes affecting all spheres of human life. Many previously familiar ideas, notions, and solutions taken for granted, are to be reinterpreted and re-evaluated under new circumstances, the main emphasis being laid on revealing the nature of the disease and searching for its effective treatment. Therefore, the preventive measures, including vaccination, are among the priorities of media discursive practice: Listen: The COVID-19 vaccine is here in New York. Many are still hesitant to get it (Times Union, January, 15 ${ }^{\text {th }}$, 2021) or Covid-19: California's Governor Reserves Vaccines for Teachers (The New York Times, February, $\left.19^{\text {th }}, 2021\right)$.

Frequently, the audience cannot accept all these ideas and messages due to many factors which have become acute in the context of COVID-19. The "stay-at-home" orders as a preventive measure, for instance, may call for the question what is to be understood "home" for many people of low social status; the effectiveness of vaccination is treated with distrust by certain categories of people who do not believe in elaboration of an effective remedy for the disease in so short time. They are looking for some alternative methods of disease prevention and treatment: Can nasal sprays help in the fight against Covid-19? (The Telegraph, February, 19 $\left.{ }^{\text {th }}, 2021\right)$. Some strata of the population are extremely at risk, first and foremost, healthcare workers and educationalists: Schools are open: All you need to know about Covid-19 testing and face mask rules (The Telegraph, March, $15^{\text {th }}, 2021$ ). The nature of the disease, as well as the perspectives of its eradication, is in the focus of research and discussions of many outstanding experts in the field: Covid eradication is unlikely ... the future of the virus is more likely to follow the flu or measles (The Telegraph, February, 20 ${ }^{\text {th }}, 2021$ ). The disputes and questions arisen are crucial both for the society and for an individual: Will the UK coronavirus death toll really be as high as we are told? (The Telegraph, April, 16 ${ }^{\text {th }}, 2020$ ). Some scientifically substantiated optimistic perspectives and recommendations contribute to a brighter light of the problem: Glasses wearers are up to three times less likely to catch Covid-19, study finds (The Telegraph, February, 20 ${ }^{\text {th }}, 2021$ ).

Communication among people during the pandemic is still problematic taking into account all restrictions imposed by governmental institutions: Exclusive: Families will be able to meet again next month (The Telegraph, February, $19^{\text {th }}$, 2021). The aforementioned examples of media discursive practice may serve as evidence of its inter-discursivity where its informative dominant is essential for language users.

COVID-19 political discursive practice covers a vast array of problems including, but not limited to, governmental and institutional issues, international relations, envisioning economic perspectives and so on. The instances of this type of discursive practice may be found in speeches of the leaders of the country, their attitude towards the problem and possible ways of its solutions: Prime Minister's address to the nation: 4 January 2021 (gov.uk, January, $4^{\text {th }}$, 2021). Manipulative and populist tactics may be traced in political debates of the candidates for presidency as it was not so along in the USA between D. Trump and J. Biden: President Biden remarks on combating the coronavirus pandemic (c-span, January, 26 $\left.{ }^{\text {th }}, 2021\right)$; Trump and Biden on COVID-19 (USA Today, October, 23 $\left.{ }^{\text {rd }}, 2020\right)$. The debates showed how serious the problem of COVID-19 pandemic is and how difficult to tackle. On the other hand, behind the problem itself there was a desire of each candidate to present oneself in a favorable light so that to win votes of the American citizens in the election. And though COVID-19 was one of the major topics of the debate, one is never deprived of the impression that it had been buried long before it started to be discussed in the debris of phrases aimed at beautifying the image of the candidates. The manipulative tactics played here the decisive role. Alongside the manipulative tactics the political discursive practice is also characterized by ambiguity and emotivity. It has an institutional character where the informative dominant is closely interrelated with a media discursive practice, the latter being considered a mediator 
between a politician and the people: Boris Johnson 'deeply sorry for every life that has been lost' to Covid (The Telegraph, January, 26 ${ }^{\text {th }}$,2021); Biden on reaching 500,000 US Covid deaths: 'We must not become numb to the sorrow' (The Guardian, February, 22 ${ }^{\text {nd }}, 2021$ ). The information dominant features are relevance, non-banality, and adequacy of presenting information. The political discursive practice is never objective or neutral as it, being a psychological phenomenon, includes both irrational and emotional levels of communication.

Finally, PSA discursive practice aims at informing people on social problems, thus, reshaping their values, standards and norms of behavior. COVID-19 PSA discursive practice possesses preventive, instructive and supportive within general information dominant. This type of discursive practice is characterized by multimodality of presenting the information about the pandemic where not only LQs as nominative units but also means of graphical and audiovisual presentation of information are used. Instructive strategy of PSA discursive practice implies presenting the information about COVID-19, its nature and major symptoms.

The slogan (Fig.1) gives essential information about the major symptoms of COVID-19 so that to shape a person's behavior and give some guidelines in case of falling ill.

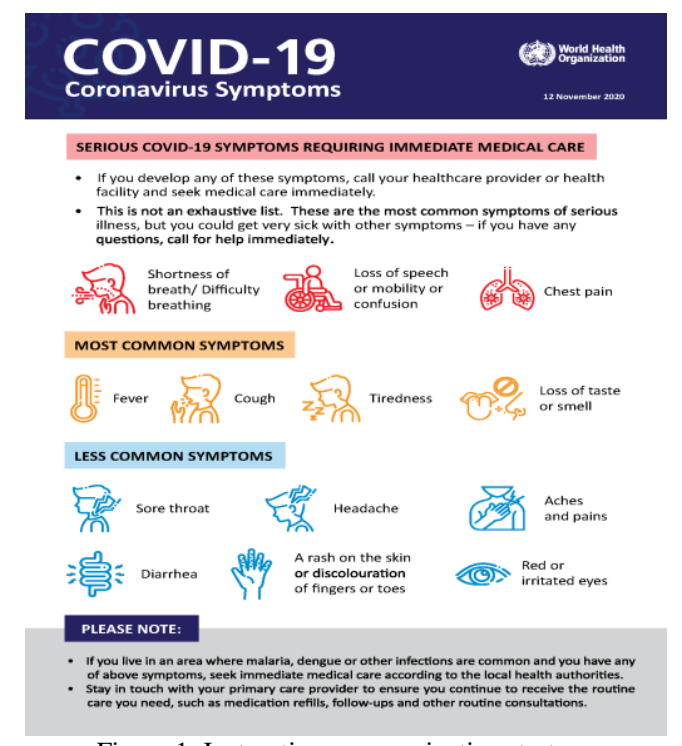

Figure 1. Instructive communicative strategy

Source: World Health Organization (https://www.who.int/images/default-source/health-topics/coronavirus/covid19-infographic-symptoms-final.tmb1920v.png)

A person is persuaded to keep to elementary rules to stay safe and sound during the COVID-19 pandemic (Fig. 2).

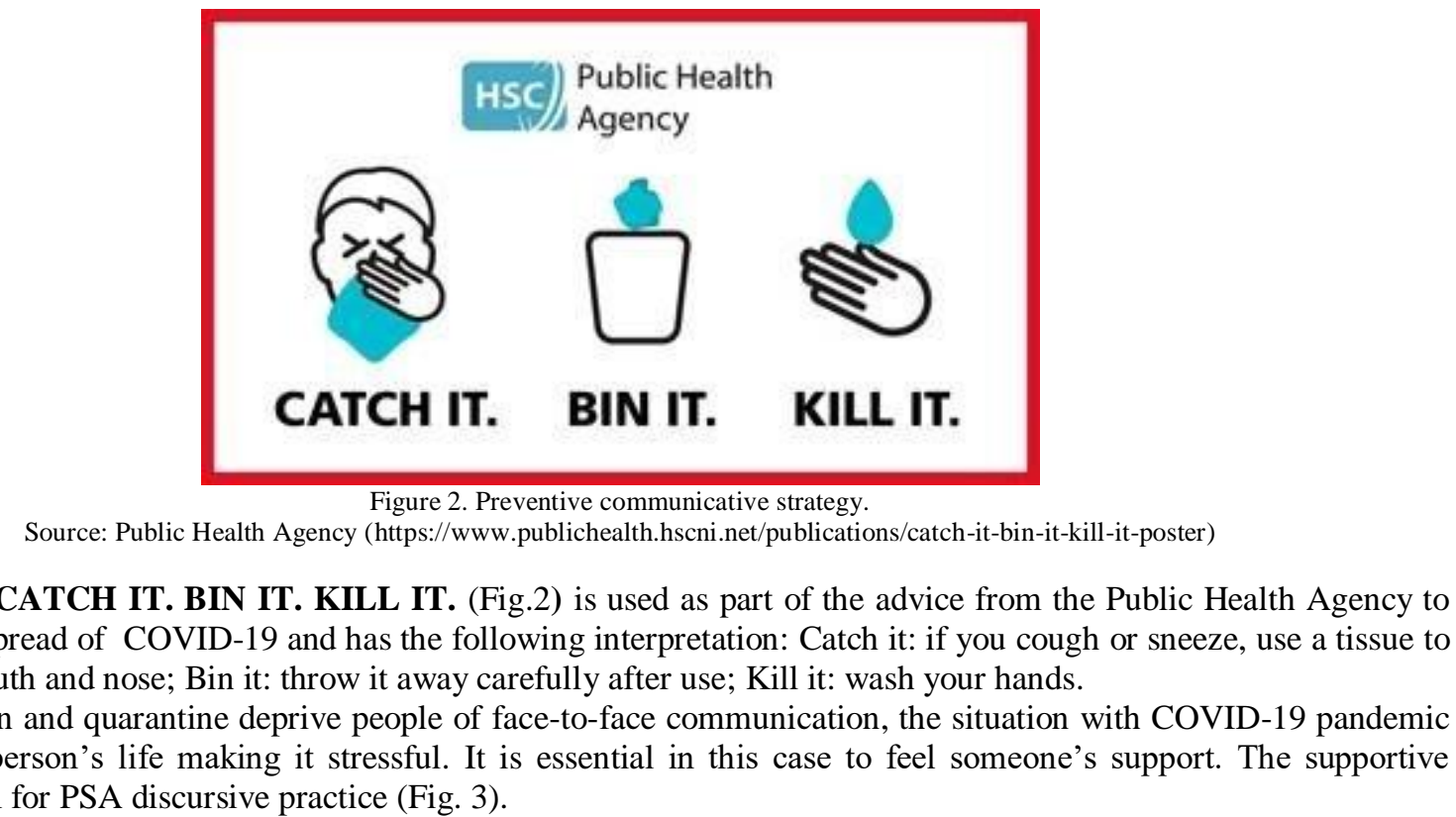

The slogan CATCH IT. BIN IT. KILL IT. (Fig.2) is used as part of the advice from the Public Health Agency to help stop the spread of COVID-19 and has the following interpretation: Catch it: if you cough or sneeze, use a tissue to cover your mouth and nose; Bin it: throw it away carefully after use; Kill it: wash your hands.

Self-isolation and quarantine deprive people of face-to-face communication, the situation with COVID-19 pandemic affects every person's life making it stressful. It is essential in this case to feel someone's support. The supportive strategy is vital for PSA discursive practice (Fig. 3). 


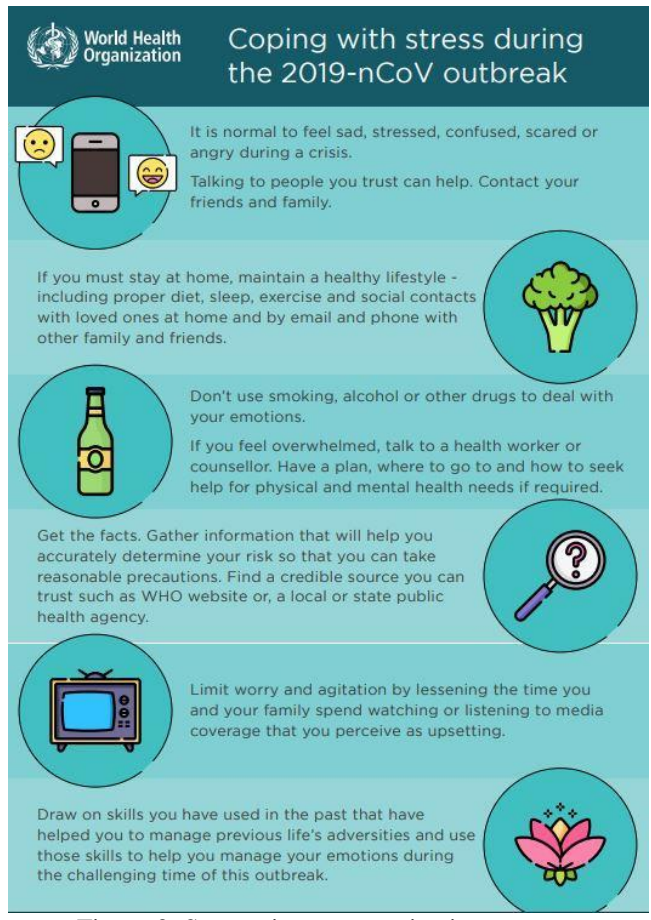

Figure 3. Supportive communicative strategy

Source: World Health Organization (https://www.who.int/docs/default-source/coronaviruse/coping-with-stress.pdf?sfvrsn=9845bc3a_8)

This example of PSA discursive practice not only enumerates the possible causes of stress under COVID-19 pandemic but also gives some tips as for alleviating the situation by drawing on the successful previous experience, developing new skills and talents.

The examples of PSA discursive practice have shown that it can influence the social behavior of the people, facilitate the harmonization of the society. It is a specific type of pragmatically-biased communication. The pragmatic potential of PSA discursive practice is determined by the mechanism of its regulatory impact on the addressee which is manifested in the formation of its intentions, activation of civil status, attitude towards the COVID-19 problems, and adjustment of the models of social behavior. "It involves the situation with the corresponding further scenario of the participants' communicative behaviour and, vice versa, the situation predicts a set of pragmatic codes" (Kravchenko, Zhykharieva, 2020).

Summing up, it is noteworthy to assert that the three different discursive practices under analysis have common information dominant which is manifested specifically in each of them. The practices complete each other and are intertwined closely with communicative intentions and targets and language means.

\section{CONCLUSION}

All things considered, COVID-19 outbreak has had the great influence on the appearance of terms and neologisms. They have been analyzed through the key methods of word formation like: semasiological; onomasiological; communicative-discursive.

Furthermore, the COVID-19 terminology arises from general medical terminology. Also, it combines and uses vocabulary units from other scientific fields like psychology, epidemiology, and sociology. The terminology is targeted at peculiarities of COVID-19 that can be subdivided into such groups as PREVENTION, INSTRUMENT, DISEASE, CONSEQUENCE. However, the general COVID-19 lexical units include the additional group, which is called BEHAVIOUR. Each of these groups is characterized by particular term-formation characteristics and pertains to different types of LK. The most common ways of formation are abbreviations, blending, borrowings, affixation. Moreover, the boundary between terminology and general LQs is quite vague, albeit it represents a new LK in LQs and indicates its innovative, pragmatic, and communicative nature realizing the available resources of the language.

The cognitive characteristics of LQs are realized in speech by virtue of various discursive practices, which are interconnected. Besides, they are targeted at providing information as well as reshaping citizens' values, standards and norms of behavior.

\section{REFERENCES}

[1] Aleksyeyeva, I., Chaiuk, T., Galitska, E. (2020), Coronaspeak as a key to coronaculture: Studying new cultural practices through neologisms. International Journal of English Linguistics, 10(6), 202-212.

[2] American Heritage (2007). Medical Dictionary. Retrieved May 12, 2021, from https://medicaldictionary.thefreedictionary.com/triage 
[3] American Heritage (2016). Dictionary of the English Language. Retrieved May 12, 2021, from https://www.thefreedictionary.com/lavage

[4] Arndt-Lappe, S., Braun, A., Moulin, C., Winter-Froemel, E. (2018). Expanding the lexicon: At the crossroads of innovation, productivity, and ludicity. In E. Winter-Froemel (Ed.), Expanding the Lexicon (pp. 1-12). De Gruyter Mouton.

[5] Bialyk, V. (2011). Lexical quantor as a linguistic unit of a language worldview. American Studies Journal, 2, 33-37.

[6] Byalyk, V. (2012). Linguistic discourse and a lexical quantor. Disputationes Scientificae, 12(1), 148-156.

[7] Bialyk, V. (2019a). Word-formation background of a lexical neo-quantor epistemology. In Efficiency Level and Necessity of Influence of Philological Sciences on the Development of Language and Literature: collective monograph, (pp. 1-17). LihaPres.

[8] Bialyk, V. (2019b). Lexical quantor genesis vs language norm dynamics. In Vectors of the Development of Philological Sciences at the Modern Stage: collective monograph, (pp. 39-56). Liha-Pres.

[9] Fairclough, N. (1992). Discourse and Social Change. Polity Press.

[10] Fauconnier, G., Turner, M. (1998). Principles of conceptual integration. In J-P. Koenig (Ed.), Discourse and cognition: bridging the gap (pp. 269-284). CSLI Publications.

[11] Fauconnier, G., Turner, M. (2002). The Way We Think: Conceptual Blending and the Mind's Hidden Complexities. Basic Books.

[12] Foucault, M. (1972). The Archeology of Knowledge. Pantheon Books.

[13] Hodge, B. (2016). Social semiotics for a complex world: Analysing language and social meaning. Wiley.

[14] Kravchenko, N. K., Zhykharieva, O. O. (2020). Sign-like pragmatic devices: pro et contra. Studies about languages, $36,70-84$.

[15] Lakoff, G., Johnson, M. (1980). Metaphors We Live by. The University of Chicago Press.

[16] Langacker, R. (1987). Foundations of Cognitive grammar (Vol. 1). Stanford University Press.

[17] Langacker, R. (1991a). Foundations of Cognitive grammar (Vol. 2). Stanford University Press.

[18] Langacker, R. (1991b). Concept, image, and symbol: the cognitive basis of grammar. De Gruyter Mouton.

[19] Langacker, R. (2000). Grammar and conceptualization. Mouton de Gruyter.

[20] Marshak, R., Keenoy, T., Oswick, C., Grant, D. (2000). From outer words to inner worlds. Journal of Applied Behaviour Science, 36(2), 229-244.

[21] Onyshko, A., Michel, S. (2010). Cognitive Perspectives on Word Formation. De Gruyter Mouton.

[22] Plag, I. (2002). Word-Formation in English. Cambridge University Press.

[23] Shepard, R. N. (1988). George Miller's data and the development of methods for representing cognitive structures. In W. Hirst (Ed.), The Making of Cognitive Science: Essays in Honor of George A. Miller (pp. 45-70). Cambridge University Press.

[24] Thorne, T. (2020). Coronaspeak - the language of Covid-19 goes vital - 2. Language and innovation (April 15, 2020). Retrieved May 12, 2021, from https://language-and-innovation.com/2020/04/15/coronaspeak-part-2-the-language-of-covid-19goes-viral/

[25] Ungerer, F., Schmid, H. J. (1996). An Introduction to Cognitive Linguistics. Longman University Press.

[26] Wüster, E. (1991). Einführung in die Allgemeine Terminologielehre und Terminologiesche Lexikographie. Romantischer Verlag.

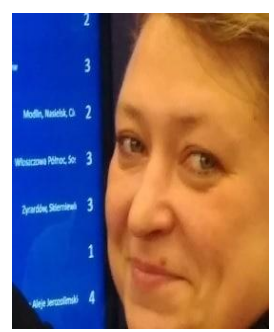

Elina Kushch. PhD in Philology, Associate Professor at the Department of Translation, Zaporizhzhia Polytechnic National University, Ukraine. E. Kushch was born in Zaporizhzhya, Ukraine on 28 March, 1975. In 2001 graduated from Kyiv State Linguistic University, Kyiv, Ukraine and got a Diploma of Teacher of English Language and Literature.

She was a teacher of English at Zaporizhzhya Technical State University, Ukraine; a post-graduate student at Kyiv State Linguistic University, Ukraine; Associate Professor at National University "Zaporiz'ka Politechnika”, 64, Zhukovskogo Street, National University “Zaporiz'ka Politechnika”, Zaporizhzya, Ukraine. The areas of scientific interest: lexical semantics, political linguistics, terminology, discourse analysis, translation studies.

As. Prof. Kushch has been the author of 115 articles published in local and international journals Kizil, M., Kushch, E. (2019). Thematic progression in English literary and legislative texts. Advanced Education, 12; Zhykharieva, O, Kushch, E. Stavtseva, V. (2021). Suggestive potential of Franklin D. Roosevelt's presidential speech 'Annual Address to the USA Congress'. Amazonia Investiga, 10 (37) as well as a monograph Varieties of English (2021) and a textbook Translation of English and Ukrainian Industry Specific Texts (2019). As. Prof. Kushch is a member of Ukrainian Association of Cognitive Linguistics and Poetics (UACLiP).

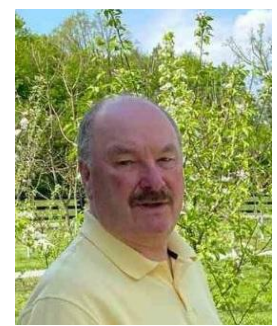

Vasyl Bialyk. Doctor in Philology, Full Professor and Chair at the Department of Communicative Linguistics and Translation, Yuriy Fedkovych Chernivtsi National University, Ukraine. V. Bialyk was born in IvanoFrankivsk, Ukraine, on 5 January, 1953. In 1975 graduated from Chernivtsi State University, Chernivtsi, Ukraine and got a Diploma of Teacher of English Language and Literature. PhD in Philology (Germanic Languages), Kyiv Shevchenko State University, Kyiv, Ukraine, 1986; Doctor of Philology (Germanic Languages), Kyiv National Linguistic University, Kyiv, Ukraine, 2013.

He was a teacher of English at Chernivtsi State University, Ukraine; a post-graduate student at Kyiv Shevchenko State University, Ukraine; Associate Professor at Chernivtsi National University, Ukraine; a visiting exchange scholar at Saskatchewan University, Canada; a visiting scholar at Manchester University, England; Professor and Chair at Chernivtsi National University, Ukraine; a Visiting Professor at Pomeranian Academy, Poland; Fulbright Scholar at the Pennsylvania State University, USA; currently works as Professor and Chair at Chernivtsi National 
University, 2 Kotsiubynsky Street, Chernivtsi National University, Chernivtsi, Ukraine, 58012. Areas of research interests: lexical semantics, terminology, discourse analysis, cognitive linguistics, translation.

Prof. Bialyk is the author of 172 publications, among them Bialyk V. (2019). Cognitive Dimension of a Lexical Quantor. Human and Culture Studies Priorities in Modern Linguistics: Trends, Tendencies and Interdisciplinary Methodology: Collective Monograph. PE Shcherbatykh O. V.; Bialyk, V. (2019). Some Criteria of Lexical Quantor Typology. Traditions and innovations in teaching philological disciplines: Collective Monograph. Liha-Press. Prof. Bialyk is a member of All-Ukrainian Translation Association (AUTA), Chairperson of NGO "Ukrainian Democratic Association" (UDA), a member of Commission on Education at Ministry of Education and Science of Ukraine, a member of the editorial boards of a number of scientific journals: Journal of the Institute of Modern Languages "Polilog", Pomeranian Academy, Slupsk, Poland; Scientific Bulletin of Germanic Philology, Chernivtsi, Ukraine; Translatorica \& Translata, Lodz, Poland. Prof. Bialyk was awarded with a medal "Excellence in Education of Ukraine", Fulbright Scholar Award.

Olena Zhykharieva. Doctor in Philology, Associate Professor at O. M. Morokhovsky Department of English Philology, Translation and Philosophy of Language, Kyiv National Linguistic University, Ukraine. O. Zhykharieva was born in Kyiv, Ukraine. In 1997 graduated from Kyiv State Linguistic University (Ukraine) and got a Specialist's degree in Philology. Majored in Philology (English and German) and Foreign Literature. PhD in Philology (Germanic Languages), Kyiv National Linguistic University, Kyiv, Ukraine, 2004. In 2019 defended the doctoral thesis English Biblical Ecodiscourse from a Linguopoetic Perspective: Construction Spaces and got the degree Doctor of Sciences in Philology (Kyiv National Linguistic University, Ukraine).

She has been working at Kyiv National Linguistic University since 2003 until the present moment. The areas of scientific interest: cognitive linguistics, biblical studies, ecodiscourse, terminology.

As. Prof. Zhykharieva has been the author of 70 articles published in local and international journals and has printed a monograph in 2018 and a textbook Practical course of the English language for business and management in 2010. Besides, As. Prof. Zhykharieva has compiled a textbook of business English Business. English. Success in collaboration with V. Stavtseva in 2020. As. Prof. Zhykharieva is a member of Ukrainian Association of Cognitive Linguistics and Poetics (UACLiP).

Viktoriia Stavtseva. PhD in Pedagogy, Associate Professor at the Department of the English Language and Translation, Kyiv National Linguistic University, Ukraine. V. Stavtseva was born in the city of Kriviy Rig (Ukraine) on 7 November, 1979. In 2001 graduated from Kyiv State Linguistic University (Ukraine) and got a Specialist's degree in Philology. Majored in Philology (English and German) and Foreign Literature. In 2014 defended the thesis Tendencies of university education development in New Zealand (XX - beginning of the XXI centuries) and got the degree Doctor of Philosophy in Pedagogy. The thesis was defended in Kyiv National Linguistic University (Ukraine).

She has been working at Kyiv National Linguistic University since 2004 until the present moment. She is teaching the second-year students as well as the graduate students English at Kyiv National Linguistic University that is situated at 73 Velyka Vasylkivska Str, Kyiv-150, Ukraine. Currently, she is interested in carrying out scientific research in political discourse as well as discursive practices.

As. Prof. Stavtseva has been the author of 15 articles that have been printed in Ukraine as well as the Academic English Glossary for Postgraduate Students that was published with cooperation with A. Zinchenko in 2017. Besides, As. Prof. Stavtseva has compiled a textbook of business English Business. English. Success in collaboration with O. Zhykharieva in 2020.

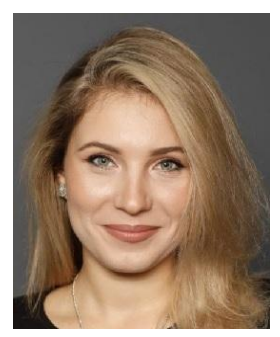

Svitlana Taran. Assistant Professor at the Department of Communicative Linguistics and Translation, Yuriy Fedkovych Chernivtsi National University, Ukraine. S. Taran was born in Kherson, Ukraine, on 6 December, 1994. In 2017 graduated from Yuriy Fedkovych Chernivtsi National University, Chernivtsi, Ukraine and got a Diploma Master of Philology.

She currently works as Assistant Professor at Yuriy Fedkovych Chernivtsi National University, 2 Kotsiubynsky Street, Chernivtsi, Ukraine. Areas of research interests: terminology, lexicography, translation.

Ms. Taran is the author of 3 articles. Taran, S. (2018). Lexicographic principles of compiling a dictionaryactivator. Scientific Bulletin of Kherson State University, 33; Taran, S. (2019). Linguistic nature of hypertext. Young Scientist, 7(71). https://doi.org/10.32839/2304-5809/2019-7-71-19; Taran, S. (2020). Structural peculiarities of Translation Studies terms in the English language. Scientific Bulletin of Yuriy Fedkovych Chernivtsi National University, 823. As. Prof. Taran is a member of All-Ukrainian Translation Association (AUTA). 